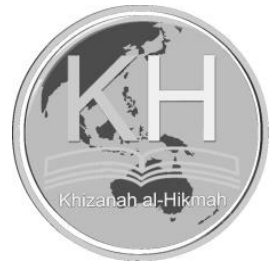

\title{
ARCHIVING HISTORICAL DATA: THREE CRITICISMS FOR THE RELIABILITY OF DIGITAL SOURCES
}

\author{
Raistiwar Pratama* \\ *Arsip Nasional Republik Indonesia \\ Email: raistiwar.pratama@anri.go.id
}

DOI: $10.24252 /$ kah.v8cf2

\begin{abstract}
ABSTRAK: Untuk data, medium merupakan informasi itu sendiri, seturut pernyataan Marshall McLuhan pada 1960-an. Terjadilah apa yang Harold K. Innis tengarai sebagai "bias media". Di tengah-tengah penghidupan kembali gagasan "sejarah total" serta pemanfaatan "data besar" dan "satu data", justru terjadi pengabaian terhadap keabsahan data seketika akses dalam jaringan terbuka bagi mereka. Serupa pernyataan "menyejarahkan sejarah"-nya Heather Sutherland dan "berpikir menyejarah"-nya Samuel Wineburg, prinsip-prinsip pengarsipan merupakan upaya penyelamatan data sejarah. Tulisan ini menguraikan kritik terhadap sumber digital historiografi yang tersaji digital.
\end{abstract}

Kata kunci: Medium; Sumber digital sejarah; kritik sumber

ABSTRACT: For data, medium is the information itself, as already stated by Marshal McLuhan in 1960's. What Harold K. Innis would have to assume as "the bias of media". In the midst of "total history" reawakening and the use of "big data" and "one data," issues on source criticism towards data are deliberately ignored as soon as online access is open for public. Similar to Heather Sutherland's "historicizing history" and Samuel Wineberg's "historical thinking", principles on records processes are among others efforts to protect historical data. This writing describes source criticisms on digital archival records.

Keywords: Medium; Digital archival records; Source criticism

\section{PENDAHULUAN}

George Orwell dalam novel 1984 menuliskan slogan the Party (Inner dan Outer), bahwa "Who controls the past controls the future. Who controls the future controls the past". Lebih lanjut "And yet the past, though of its nature alterable, never had been altered. Whatever was true now was true from everlasting to everlasting. It was quite simple. All that was needed was an unending series of victories over your own memory. 'Reality control', they called it: in Newspeak, 'doublethink'." (Orwell, 2013: 44). Siapa yang mengendalikan masa lampau, mengendalikan masa depan. Walaupun masa lampau pada dasarnya dapat berubah namun ia tidak pernah diubah. Apa saja yang pernah benar akan selalu tetap benar. Apa yang diperlukan hanyalah rangkaian kemenangan tanpa akhir atas kenanganmu sendiri. Inilah yang mewujud menjadi salah dua kebijakan Partai: "Ejaan Baru" yang menghalangi warga negara untuk memiliki kenangan dan "Nalar Ganda" yang menguasai masa lampau dan masa depan. Nubuwah fiksi Orwell tersebut lantang menujum masa depan 35 tahun kemudian melalui pembacaan terhadap arsip (dia menggunakan lema records). Terjadi kecemasan di negeri Airstrip One ketika Big Brother mengawasi siapapun.

Dewasa ini siapa yang tidak mengakses data digital sejarah? Bukankah lebih mudah, cepat, dan dalam beberapa hal mungkin saja lebih murah. Akan tetapi siapa yang sudi melakukan kritik sumber terhadap data digital sejarah atau sekurang-kurangnya keabsahan sumber setelah dialihmediakan? Seiring maraknya ketersediaan bentuk digital arsip dan manuskrip seperti 
yang dilakukan The Corts Foundation dan Arsip Nasional Republik Indonesia (ANRI) dalam Sejarah Nusantara, Koninklijk Instituut voor Taal-, Land-, en Volkenkunde (KITLV) dan Universiteit Leiden, Nationaal Archief (NA), Pusat Pengkajian Islam dan Masyarakat (PPIM) Universitas Islam Negeri (UIN) Syarif Hidayatullah, the Centre for the Study of Manuscripts and Culture (CSMC) Universität Hamburg, dan Arcadia melalui Digital Repository of Endangered and Affected Manuscript in Southeast Asia (Dream Sea), Masyarakat Pernaskahan Nusantara (Manassa), dan masih banyak lagi dewasa ini, maka perlu bagi setiap pengguna data digital sejarah untuk mengetahui bagaimana proses pendigitalan itu berlangsung dan standardstandard informasi kearsipan apa saja yang terkait.

Tulisan ini menyangsikan sebagian pernyataan yang Jill Campbell-Miller dan Ryan Kirkby kemukakan bahwa "Yet while historians may be familiar with how to critique the sources themselves, rarely do we look up from a given document and examine the place where it is located, or think about how the document arrived in the archives." (http://activehistory.ca/2018/07/historian-meet-archivist-researching-the-history-of-complexorganizations/, diakses pada 4 Februari 2019). Menurut keduanya, sejarawan terbiasa melakukan kritik sumber namun abai memperhatikan pemberkasan, penyimpanan, dan akuisisi arsip. Sayangnya keduanya tidak memaparkan lebih lanjut kritik seperti apa yang diterapkan pada arsip digital. Tulisan ini melengkapinya dengan memaparkan tiga kritik (arsip) digital. Sebelumnya, definisi arsip digital dan kritik sumber dalam metode sejarah diuraikan.

Mengamini pernyataan Jo Guldi dan David Armitage (2014: 12, 88 - 116) dalam History Manifesto bahwa "big data" membuka lebar kemungkinan kajian sejarah durasi panjang (longée durée) namun juga memerlukan "big questions". Lagi-lagi, sebagaimana Campbell-Miller dan Kirkby, Guldi dan Armitage juga abai melakukan kritik digital. Keduanya justru fokus pada heuristik, interpretasi, dan historiografi. Kalaupun ada, hanya kritik intern bukan ekstern, apalagi gabungan keduanya. Sekalipun kritik digital sedikit berbeda dari kritik sumber pada umumnya, namun secara prinsip kritik tersebut dapat diterapkan dan dikembangkan pada data digital sejarah.

\section{Data: Berubah dan Terlahir Digital}

Menurut ISO 5127:2017, informasi adalah data yang diproses (processed), ditata (organized), dan berhubungan (correlated) untuk menghasilkan makna. Adapun masih menurut ISO, kali ini ISO 15489-1:2016 Records Management (lihat juga SNI 8642:2018 Pengelolaan Arsip), arsip adalah informasi yang diciptakan (created), diterima (received), dan dipelihara (maintained) sebagai bukti (evidence) dan aset bagi organisasi atau seseorang untuk memenuhi kewajiban legal atau transaksi. Terlihat hubungan antara arsip, informasi, dan data. Hubungan yang saling melengkapi. Tidak berbeda dan membedakan.

Menurut Theo Thomassen (2001: 374), "records are process-bound information" sedangkan "a record is information that can be retrieved in the form of a document...." Seturut pendekatan daur hidup, tidak semua "records" dapat menjadi "archives" atau kadang-kadang disebut "archival records". Lebih lanjut, Thomassen menyatakan bahwa "Records are linked to coherent work processes". Seakan-akan menjawab kesangsian McLuhan, Thomassen (2002: 384) menyatakan bahwa "makna dari isi" bergantung pada struktur, bentuk, dan konteks. Terdapat hubungan-hubungan antara data isi (the content data), arsip (the records), fungsi kinerja (the generating functions), dan proses yang terjadi sepanjang kegiatan dan kerja pengarsipan yang mengiringinya. Tanpa pemahaman memadai terhadap hubungan-hubungan tersebut, maka mudah terjadi pemalsuan atau kerancuan pemahaman terhadap "makna dari isi". Perlu juga dipahami bahwa baik "records" maupun "archives" bukanlah "pengganti" (surrogates) dunia nyata namun "perwakilan" (representations) apa yang juru tulis dan sekretaris pikirkan ketika mendokumentasikan menurut perintah atasan mereka, bahkan hanya "perwakilan jauh" (remote representations) kenyataan, sisa-sisa, campuran, terpecah, dan acapkali "dipisahkan dari konteks" (decontextualised).

Pernyataan sama seperti yang pernah Verne Harris kemukakan perihal kekuasaan, memori, dan arsip di Afrika Selatan. Arsip, Harris definisikan sebagai (2002: 63 - 4) "... 
constructed windows into personal and collective processes". Mengenai arsip yang bernilai sejarah, jamak dikenal kalangan arsiparis sebagai arsip statis atau archival records atau documentary records atau historical records, menurut Harris $(2002: 64,84)$ adalah "... a sliver of social memory ... a sliver of documentary record ... a sliver of a window into the event ... is best understood as a sliver of a sliver of a sliver of a window into process." Hanya setitik dari keseluruhan kejadian atau peristiwa.

\section{Melampaui Kritik, Memperbarui Diplomatik}

Dalam metode sejarah yang terdiri dari lima tahap menurut Kuntowijoyo (1997: 89 105), terdapat tahap verifikasi yang dilakukan setelah heuristik dan sebelum interpretasi. Verifikasi atau kritik sejarah atau menguji keabsahan sumber yang membawahi autentisitas dan kredibilitas. Autentisitas merupakan kritik terhadap piranti yang merekam informasi sedangkan kredibilitas merupakan kritik terhadap informasi yang direkam. Mengenai heuristik, Sartono Kartodirdjo (1992: 31) menulis, "Pada hakikatnya, sejarawan tidak hanya berkewajiban menemukan dokumen apa, di mana, dan bagaimana, tetapi yang lebih penting ialah dokumen yang mana." Dapat penulis tambahkan, dokumen seperti apa atau lebih tepatnya dokumen yang bermediumkan apa.

Mengutip pertanyaan John Tosh (2010: ) "How did they come to be made available?". Juga menurut Laura Schmidt (2011: 1) “... to make them available for use.” Lebih lanjut, Kartodirdjo menulis, "Jelaslah bahwa dalam hal ini persoalan-persoalan sejarawanlah yang menjadi penentu." Apakah hanya sejarawan yang menentukan? Apabila ternyata sejarawan hanya fokus pada informasi, bukan pada piranti; terutama abai melihat keterkaitan organis antara piranti dan informasi, bagaimana piranti amat berpengaruh pada informasi. Apa yang menarik adalah pernyataan Kartodirdjo bahwa "Tidaklah cukup bahwa dokumen terhindar dari pembinasaan; sejarawan berkewajiban menyelamatkan dan melacaknya." Menyelamatkan tidak hanya fisik dokumen namun juga konteks peristiwa yang mengemuka melalui interaksi piranti dan informasi, serta melacak keberadaan draf, salinan, kopi, tembusan, per tinggal, dan metadata. Bukan hanya alih media dan digitasi, tetapi juga konversi dan migrasi.

Akses digital dalam jaringan (on line) cenderung menghilangkan kritik ekstern, lalu semata-mata fokus melakukan kritik intern. Padahal menurut McLuhan medium merupakan informasi itu sendiri. Medium bukan hanya perantara namun menentukan keterbacaan informasi dan dapat memberikan konteks. Inilah yang Heather Sutherland sebut "menyejarahkan sejarah", bagaimana sejatinya arsip bukan hanya apa yang terbaca namun juga tempatnya dalam konteks peristiwa sejarah. "Berpikir menyejarah" adalah bagaimana memahami keberadaan sumber dan kaitannya dengan pelaku sebagai agen. Konteks tersebut hanya dapat dipahami dengan memahami hubungan antara isi dan medium arsip. Bukan lantas menegasikan salah satu dari keduanya tetapi perlu pemahaman kritik sumber yang menggabungkan praktek kritik intern dan ekstern, sebagaimana praktek riset sejarah yang selama ini sejarawan dan peneliti sejarah lakukan pada arsip bermediumkan kertas.

Harold K. Innis (1964; Comor, 2001) menguraikan bermacam-macam bias terhadap komunikasi yang sejatinya berpusat pada dua bentuk media: bias zaman (time-biased media) dan bias tempat (space-biased media). Perbedaan utama keduanya terletak pada ketersebaran jangkauan kekuasaan dan tentu saja media. Semakin ringan media maka semakin luas jangkauannya, begitu pun sebaliknya. Jangkauan itu tidak semata kekuasaan ketika fungsi suatu organisasi masih sedang berlangsung namun juga keberlangsungan akses sumber kontemporer (sebagian menyebutnya sumber primer) sejak arsip tersebut tercipta, digunakan untuk kepentingan administratif, dan dimanfaatkan kelak untuk kepentingan riset. Arsip tersebut hanya dapat lestari apabila media arsip dapat tahan lama; bias zaman.

Kedua macam bias tersebut tidak mesti dipahami secara terpisah tetapi terdapat pula bias yang merupakan gabungan dialektik keduanya. Namun ketika masih digunakan untuk kepentingan administratif (arsip dinamis) atau kekuasaan/ pemerintahan sedang berlangsung maka arsip tersebut mengidap bias ruang. Perkamen dan kertas dapat mengatasi bias ruang (jangkauan luas) namun harus mengalah dari bias waktu. Batu (mungkin kayu dan logam) dapat 
mengatasi bias waktu (tahan lama) namun harus mengalah dari bias ruang karena kesulitan mengangkutnya. Arsip digital mengidap sekaligus kedua bias tersebut. Sepintas menguntungkan karena tidak membutuhkan tempat penyimpanan yang luas dan mudah dibawa. Namun secara jangka panjang apakah demikian? Perangkat lunak dan perangkat keras yang begitu cepat berganti. Bentuknya ada, tetapi apakah akan tetap dapat "dibaca"?

Luciana Duranti (1989: 8) mengajak untuk menghidupkan kembali diplomatik bukan berdasarkan Ilmu Sejarah-dengan kata lain, bukan Diplomatik sebagai ilmu bantu bagi Ilmu Sejarah—namun berdasarkan kerangka pikir diplomatik itu sendiri. Menurutnya:

However, the principles, concepts, and methods of diplomatics are universally valid and can bring system and objectivity to archival research into documentary forms, that is, a higher scientific quality. It is well known that the archivist's research into the nature or character of records has purposes different from that of the historian. Thus, it is not advisable for archivists to adopt diplomatic methodology as it has been filtered through the needs of scholars of history. Rather, it is appropriate for them to extract directly from the original science of diplomatics those elements and insights which can be used for their work, and to develop them to meet contemporary needs.

Sekalipun begitu, diplomatik khusus pengelolaan kearsipan (special diplomatics of records management) perlu dikembangkan sesuai prinsip kearsipan kontemporer. Duranti (1989: 17) pun menyatakan bahwa diplomatik kearsipan: "diplomatics is the discipline which studies the genesis, forms, and transmission of archival documents, and their relationship with the facts represented in them and with their creator, in order to identify, evaluate, and communicate their true nature."

Apa yang Duranti gagas (sebanyak 6 seri artikel dalam Archivaria berturut-turut sepanjang 1989 - 1991) serupa dengan apa yang John Tosh (2002) kemukakan mengenai kritik sumber. Bagi Tosh, kritik sumber (source criticims) memerlukan pendekatan diplomatik tidak hanya secara ekstern tetapi justru secara intern. Lebih lanjut, Tosh menguraikan tiga macam kritik: asal usul (provenance), isi (content), dan bentuk (form). Medium serupa dengan bentuk. Isi merupakan informasi.

Sebelum melakukan tiga kritik ini, perlu pula diketahui 3 proses dibalik digitalisasi arsip. Proses itu antara lain pemilihan arsip (baik media maupun subjek) dan ketersediaan sarana bantu temu kembali (daftar dan inventaris), pengalihan media arsip (alat, pelaku, dan tempat), dan keberlangsungan akses (baik di ruang baca maupun dalam jaringan). Setiap pengguna arsip digital mesti mengetahui proses tersebut untuk membantu menerapkan kritik lanjutan.

\section{Kritik Pemberkasan}

Dengan segala kemudahan yang Sean Kheraj kemukakan bahwa teknologi digital memberikan kemudahan pada tiga hal terkait sejarah: kajian, pengajaran, dan sejarah publik; tetap saja sejarawan mesti mencermatinya (https://www.digitalhist.com/2018/11/23/meaning-making-in-the-digital-age/, diakses pada 27 Maret 2019). Laura Schmidt (2011: 5) memandu kita untuk meneliti dengan menggunakan arsip digital. Schmidt merasa perlu untuk memberikan peringatan keras bahwa "However, be aware that digital collections often reflect just a fraction of the total holdings of a repository." Seberapa sering kita begitu saja merasa puas setelah menemukan selembar foto atau dokumen atau peta, tanpa merasa perlu memperhatikan bahwa sebenarnya itu hanya merupakan bagian (amat) kecil dari keseluruhan informasi yang memberkas pada arsip digital. Ini semakin membenarkan pernyataan Harris bahwa arsip saja sudah merupakan setitik dari seluruh peristiwa apalagi ketika sudah berbentuk digital maka semakin mempersulit memahami utuh suatu peristiwa.

Pemberkasan erat terkait dengan asas asal usul (terjemahan untuk principle of provenance) yang pada dasarnya merupakan pilar Ilmu Kearsipan (Duchein, 1977: 19; 1992: 66; Michetti, 2017: 229, 245). Thomassen (2002: 383) menguraikan pernyataan menarik mengenai asas asal-usul, "At the level of the record this means respect for the form. This is the domain of 
diplomatics from time immemorial. At the level of the archive this means respect for the structure (the principle of original order) and the context of creation (the principle of provenance). Respecting form, structure and context of creation means maintaining the relations between the content data, the relations between the records and the relations between the records and the generating functions and processes."

Terry Cook (1997: 21) menyatakan bahwa pengolahan arsip (arrangement dan description) selalu terkait dengan provenance (dan original order). Apabila arrangement dan description merupakan metode kearsipan, maka provenance dan original order merupakan metodologinya. Menurut Duchein (1977: 19; 1992: 66) dan Coeure dan Duclert (2001: 21) provenance atau respect des fonds berasal dari Perancis yang dirumuskan pada 1841 oleh Natalis de Wailly, sejarawan sekaligus arsiparis Arsip Nasional Perancis (Archives nationales); dan original order atau strukturprinzip berasal dari Jerman, tepatnya Prussia, pada 1880 oleh para arsiparis the Royal Archives of Prussia.

Melampaui kepentingan (legitimasi) historis, provenance dan original order justru memberikan pemahaman atas konteks sezaman para pencipta arsip yang meliputi struktur dan fungsinya. Para peneliti sejarah tentu lebih merasa dipermudah untuk mengetahui informasi perihal (information of) para pencipta arsip bukan hanya informasi mengenai (information about) para pencipta arsip. Penerapan prinsip kembar tersebut sebagai metodologi kearsipan dapat mengungkapkan siapa sebenarnya pihak pengirim dan penerima informasi, siapa yang menciptakan informasi, untuk tujuan apa, dan mengenali dua fungsi (fasilitatif [dinamis] dan terutama fungsi substantif [statis]) lembaga pencipta arsip.

Setiap level informasi pencipta arsip dapat memperlihatkan bagaimana bangunan informasi dibentuk. Level fonds, sesekali juga sub-fonds, memperlihatkan siapa pencipta arsip dan kemandiriannya dalam pengambilan keputusan. Level series, sesekali juga sub-series, memperlihatkan fungsi substantif pencipta arsip, dengan kata lain struktur organisasinya. Level file memperlihatkan permasalahan yang telah memberkas dan pembahasan yang telah tuntas. Akhirnya, apabila memungkinkan atau karena kendala pemberkasan yang tidak tuntas maka level item memperlihatkan surat masuk dan surat keluar. Itulah yang dikenal kalangan arsiparis sebagai pemahaman multi-level description. Akan tetapi, telah terjadi pergeseran dari pendekatan yang berpusat pada fonds sebagai pencipta arsip menjadi pendekatan fungsi pada level series yang merekam fungsi substantif setiap pencipta arsip. Secara berturut-turut, level file sejajar dengan kegiatan yang merekam kegiatan menjadi berkas kegiatan dan level item sejajar dengan transaksi.

Apabila seksama kita perhatikan setiap surat undangan, selalu terdapat keterangan pada bagian bawah kiri, seperti tembusan dan per tinggal atau arsip. Inilah yang dikenal sebagai tingkat perkembangan arsip, yang juga mencakup salinan dan/ atau kopi. Apabila telah memberkas pada level file dan kemudian pada level series, maka informasi perihal suatu kejadian telah utuh terekam. Memperhatikan tingkat perkembangan arsip, maka setiap item berjejaring dengan banyak pencipta arsip bahkan mungkin dalam waktu bersamaan. Maka dari itu fonds yang cenderung struktural telah usang. Prinsip dwitunggal pada mulanya mengutamakan fungsi dan kini cenderung strukturis. Pendekatan strukturis menengahi pendekatan struktural dan fungsional.

Pada September 2016, ICA mulai menerbitkan draf pertama Records in Context: A Conceptual Model for Archival Description (RiC-CM) yang menggabungkan pedoman/ manual kearsipan sebelumnya General International Standard of Archival Description (ISAD-G), International Standard Archival Authority Record for Corporate Bodies, Persons and Families (ISAAR [CPF]), International Standard for Describing Institutions with Archival Holdings (ISDIAH), dan International Standard for Describing Functions (ISDF) yang terbit sepanjang 1988 - 2008. Dalam laporan Expert Group on Archival Description (EGAD), Daniel Pitti menyatakan bahwa provenance dan original order masih menjadi dasar, prinsip, dan aturan dalam RiC-CM. Definisi provenance, menurut RiC-CM, meliputi dua hal: respect des fonds dan respect for original order. Pitti mendefinisikan provenance sebagai prinsip di mana fonds dan original order mesti 
diperhatikan. Serupa dengan Duchein dan Mant, RiC-CM hingga akhirnya terbit kedua bagian pada 2020 (2016: 4 - 5; 2020) juga memberikan kritik dan menguraikan definisi yang kiranya lebih sesuai.

\section{Kritik Alih Media}

Arsiparis yang selama ini-dan memang hanya-mengolah arsip bermediumkan kertas memahami frasa "alih media" sebagai kerja penggantian medium dari kertas menjadi bukankertas yang dipahami sebagai "media baru", lawan dari "media lama". Pada mulanya media baru hanya mencakup bentuk mikrofilm dan microfiche. Seketika kita sadari bahwa kekuranganatau justru kelebihan?-arsip media baru tersebut bergantung pada ketersediaan dan kesesuaian "alat baca". Itu pun harus berpacu dengan waktu serta lembaga kearsipan dan praktisi kearsipan bersiap melakukan antisipasi. Padahal rintisan percobaan mikrografik yang mendasari mikrofilm dan microfiche telah terjadi sejak akhir paruh kedua abad XIX dan dapat bertahan selama 500 tahun sejak dialihmediakan. Namun teknologi telah mendesaknya atas nama penghematan. Pada dasawarsa 1930, teknologi Optical Character Recognition (OCR) mulai menggantikan, hingga mengemukalah Portable Document Format (PDF). Mikrografik sejatinya masih memberikan konteks karena dia mengalihkan secara apa adanya, sesuai posisi semula, hanya saja tidak lagi bermediumkan kertas. Menurut Craig Saper, "...digital documents usually omit the context...obscure the historical context of that material" (https://www.theatlantic.com/technology/archive/2018/07/microfilm-lasts-half-amillennium/565643/?utm source=feed, diakses pada 19 Januari 2019).

Alih media secara garis besar terdiri dari dua ragam: konversi dan migrasi. Menurut ISO Records Management 15489-1:2016, konversi adalah proses pengubahan arsip dari satu bentuk ke bentuk lain (process of changing records from one format to another). Menurut ISO Management Systems for Records 30300:2011, migrasi adalah proses pemindahan arsip dari satu konfigurasi perangkat keras atau perangkat lunak ke konfigurasi lain tanpa mengubah bentuk (process of moving records from one hardware or software configuration to another without changing the format).

Menghadapi maraknya penggunaan beragam aplikasi sejak dasawarsa 1990-an, Jeff Rothenberg (https://www.clir.org/pubs/reports/preface/, diakses pada 7 Februari 2019) menulis:

"The best way to satisfy the criteria for a solution is to run the original software under emulation on future computers. This is the only reliable way to recreate a digital document's original functionality, look, and feel. Though it may not be feasible to preserve every conceivable attribute of a digital document in this way, it should be possible to recreate the document's behavior as accurately as desired-and to test this accuracy in advance."

"The implementation of this emulation approach involves: (1) developing generalizable techniques for specifying emulators that will run on unknown future computers and that capture all of those attributes required to recreate the behavior of current and future digital documents; (2) developing techniques for saving-in human-readable form-the metadata needed to find, access, and recreate digital documents, so that emulation techniques can be used for preservation; and (3) developing techniques for encapsulating documents, their attendant metadata, software, and emulator specifications in ways that ensure their cohesion and prevent their corruption. The only assumption that this approach makes about future computers is that they will be able to perform any computable function and (optionally) that they will be faster and/or cheaper to use than current computers."

Selain emulasi, telah berkembang pula Semantic Web (SW) oleh Tim Berners-Lee yang menyediakan kerangka bersama (common platform) sehingga data bisa dibagi-pakai lintas aplikasi, lembaga, dan komunitas. Berbeda dari emulasi yang mensyaratkan peladen (server) pribadi, SW menyediakan peladen serupa cloud yang bisa diakses siapa saja, di mana saja, dan kapan saja. 


\section{Kritik Metadata}

Menurut ISO Managing metadata for records - Conceptual and implementation issues 23081-1:2017, metadata arsip adalah informasi terstruktur atau semi-terstruktur, yang memungkinkan penciptaan, pengelolaan, dan penggunaan arsip berlangsung sepanjang waktu serta dalam dan lintas wilayah ("...structured or semi-structured information, which enables the creation, management, and use of records through time and within and across domains").

Metadata menyediakan konteks atas struktur arsip digital serupa dengan arsip kertas. Dus, metadata merupakan perangkat untuk melakukan kritik ekstern bagi sejarawan. Salah satu panduan untuk memahami dan menerapkan metadata pada arsip adalah Dublin Core Metadata Initiative (DCMI) yang merupakan platform standar metadata bagi-pakai,. Menurut DCMI, diadopsi menjadi ISO 15836-1:2017, metadata harus mencakup 15 elemen sederhana: Pencipta (Creator), Contributor, Penerbit (Publisher), Judul (Title), Kurun waktu (Date), Bahasa (Language), Format, Bahasan (Subject), Uraian (Description), Identifier, Keterkaitan (Relation), Sumber (Source), Type, Cakupan (Coverage), dan Hak cipta (Rights); dan 3 elemen tambahan: Khalayak (Audience), Asas Asal-Usul (Provenance), dan Pemangku Hak (Rightsholder) (http://dublincore.org/resources/metadata-basics/, diakses pada 27 Maret 2019).

Selain DCMI, terdapat satu standar mengenai metadata yaitu ISO Managing metadata for records - Conceptual and implementation issues 23081-2:2009 menyatakan bahwa metadata terdiri dari enam cakupan: Identity, Description, Use, Event plan, Event history, dan Relation. Bagi arsiparis, elemen metadata serupa dengan elemen deskripsi yang mendapati sebagian elemen merupakan essential dan sebagian lainnya merupakan optional. Pada dasarnya elemen metadata memberikan konteks terhadap penciptaan dan penciptaan ulang informasi,

Kritik ekstern yang mencakup kualitas kertas/media, ejaan, bentuk tulisan, dan segel dapat disematkan pada elemen metadata yang mungkin saja tidak tercakup dalam standar metadata kearsipan. Sejarawan harus mampu merumuskan elemen sejarah dalam standar metadata. Inilah yang penulis sebut sebagai elemen kritik ekstern arsip digital. Sebagaimana sejarawan mampu melakukan kritik ekstern pada arsip kertas, begitu pula yang harus sejarawan lakukan pada arsip digital. Prosedur kritik yang tidak abai pada proses bukan hanya hasil, pada konteks bukan hanya struktur, dan pada medium bukan hanya informasi.

\section{Kesimpulan}

Ikut merasakan kecemasan karena rentannya media digital dan ketergantungan informasi yang begitu kritis pada mediumnya, Rick West, pengolah data di Google, berkata "We may [one day] know less about the early 21st century than we do about the early 20th century. The early 20th century is still largely based on things like paper and film formats that are still accessible to a large extent; whereas, much of what we're doing now - the things we're putting into the cloud, our digital content - is born digital. It's not something that we translated from an analog container into a digital container, but, in fact, it is born, and now increasingly dies, as digital content, without any kind of analog counterpart." Kita-tidak hanya sejarawan-mungkin sebentar lagi menjelang abad kegelapan digital yang bisa saja keadaannya lebih parah daripada kegelapan Abad Pertengahan karena informasi tidak "melekat" pada satu medium yangmengutip Innis-mengatasi bias waktu dan bias tempat sekaligus (http://activehistory.ca/2018/11/meaning-making-in-the-digital-age/, diakses pada 4 Februari 2019; https://www.pri.org/stories/2018-01-01/scientists-warn-we-may-be-creating-digitaldark-age?fbclid=IwAR0CmAS9DKf-I8sForQDiPxRFXjBAQ0onskpFzCV0ScTTdm 7FpxqteAxyo,

diakses pada 18 Februari 2019). Pilihannya bukan terletak pada medium apa yang kita pilih tetapi bagaimana cara kita memahami keterkaitan setiap medium dengan suatu informasi pada satu waktu dan ketersediaan akses pada waktu lain.

Tulisan singkat ini sama sekali tidak ingin melawan apa yang Karl R. Popper gugat perihal "historicism". Popper (1953: 7) menyatakan bahwa "historicism" adalah "an approach to the social sciences which assumes that historical prediction is their principal aim ... to lay bare the law of evolution of society in order to foretell its future.". Sejatinya tulisan ini hanya ingin membubuhkan konteks dan subteks yang dapat memperbaiki fungsi kritik sumber terhadap 
arsip digital sehingga sejarawan tidak lantas begitu saja mengikuti apa yang tersaji di suatu situs atau portal tanpa melihat keterkaitan antarteks, teks dengan dokumen, antardokumen, dokumen dengan berkas (file), antarberkas, dan berkas dengan fungsi (series) pencipta arsip. Keterkaitan bahkan konteks itu akan semakin sulit ketika arsip telah berubah bentuk (baik karena migrasi maupun konversi) menjadi digital.

Pernyataan bahwa "masa lampau untuk masa lampau" justru untuk memperkuat kegunaan sejarah atau, seperti tulis Kuntowijoyo (1997: 191), melakukan "rekonstruksi masa lampau" sebisa mungkin. Di situs SP Lohia Collection, upaya lembaga bukan-pemerintahan untuk menyediakan akses atas arsip dan manuskrip digital tanpa bayaran (http://splrarebooks.com/, diakses pada 22 Januari 2019), tertulis, "The wisdom of the past is priceless, but we risk losing it forever when physical records decay."

Keberadaan informasi itu tidak ternilai dan sangat tergantung pada bentuk fisiknya serta terkait erat dengan konteks dan bagaimana itu bisa terhubung dengan penafsiran pembaca, sebagaimana tulis Samuel Wineberg (2001) bahwa "We all are historians". Ucapan yang sama pernah diucapkan Carl Becker, "Everyman his own historian." Seiring perkembangan digital yang merambah segala bidang, maka kritik sumber menjadi penting tidak hanya bagi sejarawan namun bagi siapapun (data analyst, data specialist, information specialist, reference librarian, dan lain-lain) yang memiliki akses terhadap—dan ingin mendapatkan-informasi.

\section{REFERENCES}

Badan Standardisasi Nasional. (2018). Standar Nasional Indonesia 8642:2018 Informasi dan dokumentasi - Pengelolaan arsip - Bagian 1: Konsep dan prinsip. Jakarta: Badan Standardisasi Nasional.

Comor, E. (2001). Harold Innis and 'The Bias of Communication'. Information, Communication and Society 4 (2): 274-94.

Cook, T. (1996). What is Prologue is the Past: a History of Archival Ideas since 1898 and the Future Paradigma Shift. Archivaria 43:17-63.

Duchein, M. (1977/1983). Theoretical Principles and Practical Problems of Respect de Fonds in Archival Science. Archivaria 16: 64-82.

Duranti, L. (1991). Diplomatics: New Uses for an Old Science (Part VI). Archivaria 33: 6-24.

Duranti, L. (1989). Diplomatics: New Uses for an Old Science (Part I). Archivaria 28: 7-27.

Guldi, J., \& Armitae, D. (2014). History Manifesto. Cambridge University Press.

Harris, V. (2002). The Archival Sliver: Power, Memory and Archives in South Africa. Archival Science 2: 63-86.

http://activehistory.ca/2018/07/historian-meet-archivist-researching-the-history-of-complexorganizations/, diakses pada 4 Februari 2019.

http://activehistory.ca/2018/11/meaning-making-in-the-digital-age/, diakses pada 4 Februari 2019.

http://splrarebooks.com/, diakses pada 22 Januari 2019.

https://www.digitalhist.com/2018/11/23/meaning-making-in-the-digital-age/, diakses pada 27 Maret 2019.

https://www.pri.org/stories/2018-01-01/scientists-warn-we-may-be-creating-digital-darkage?fbclid=IwAR0CmAS9DKf-I8sForQDiPxRFXjBAQ0onskpFzCV0ScTTdm_7FpxqteAxyo, diakses pada 18 Februari 2019.

https://www.theatlantic.com/technology/archive/2018/07/microfilm-lasts-half-amillennium/565643/?utm_source=feed, diakses pada 19 Februari 2019.

Innis, H. A. (1964). The Bias of Communication. Toronto: University of Toronto Press.

International Council on Archives Experts Group on Archival Description. (2020) Records in Contexts: A Conceptual Model for Archival Description. Cleveland: International Council on Archives.

International Council on Archives. (2016). Records in Context: An international standard for archival description, Progress report. Cleveland: International Council on Archives. 
International Organization for Standardization (2011). 30300. Information and documentation Management systems for records - Fundamentals and vocabulary. Jenewa: International Organization for Standardization.

International Organization for Standardization. (2009). 23081 - 2. Information and documentation - Managing metadata for records - Part 2: Conceptual and implementation issues. Jenewa: International Organization for Standardization.

International Organization for Standardization. (2016). 15489 - 1. Information and documentation - Records management - Part 1: Concepts and principles. Jenewa: International Organization for Standardization.

International Organization for Standardization. (2017). 23081 - 1: Information and documentation - Records management processes - Metadata for records - Part 1: Principles. Jenewa: International Organization for Standardization.

International Organization for Standardization. (2017). 5127. Information and documentation Foundation and vocabulary. Jenewa: International Organization for Standardization.

Kartodirdjo, S. (1992). Pendekatan Ilmu Sosial dalam Metodologi Sejarah. Jakarta: Gramedia Pustaka Utama.

Kuntowijoyo. (1997). Pengantar Ilmu Sejarah. Yogyakarta: Yayasan Bentang Budaya.

McLuhan, M. (1960). Understanding Media: The Extensions of Man. Massachusetts: Massachusetts Institute of Technology Press.

Michetti, G. (2017). Provenance in the Archives: The Challenge of Digital, in Archives in Liquid Times. Edited by Frans Smit. 's Gravenhage: Stichting Archiefpublicaties.

Orwell, G. (2013). Nineteen Eighty Four. London: Uberon Books Ltd.

Rothenberg, J. (1999). Avoiding Technological Quicksand: Finding a Viable Technical Foundation for Digital Preservation. London: Council on Library and Information Resources Commission on Preservation and Access.

Schmidt, L. (2011). Using Archives: A Guide to Effective Search. Chicago: Society of American Archivists.

Sutherland, H. (2008). Meneliti Sejarah Penulisan Sejarah dalam Perspektif Baru Penulisan Sejarah Indonesia. Diedit Henk Schulte Noordholt, Bambang Purwanto, dan Ratna Saptari. Jakarta: Buku Obor dan Koninklijke Instituut voor Tall-, Land- en Volkenkunde Jakarta.

Thomassen, T. (2001). A First Introduction to Archival Science. Archival Science 1: 373 - 385.

Tosh, J. 2002. The Pursuit of History; Aims, Methods and New Directions in the Study of Modern History. Revised 3rd Edition. Great Britain: Pearson Education Limited.

Wineburg, S. (2001). Historical Thinking and Other Unnatural Acts. Philadelphia: Tempe University Press. 